\title{
Thermal adaptation of soil microbial respiration to elevated temperature
}

\author{
Mark A. Bradford, ${ }^{1 *}$ Christian A. Davies, ${ }^{1}$ Serita D. Frey, ${ }^{2}$ Thomas R. Maddox, ${ }^{1}$ Jerry M. \\ Melillo, ${ }^{3}$ Jacqueline E. Mohan, ${ }^{1,3}$ James F. Reynolds, ${ }^{4}$ Kathleen K. Treseder ${ }^{5}$ and Matthew \\ D. Wallenstein ${ }^{6}$
}

${ }^{1}$ Odum School of Ecology, University of Georgia, Athens, GA 30602, USA

${ }^{2}$ Department of Natural Resources, University of New Hampshire, Durham, NH 03824, USA

${ }^{3}$ The Ecosystems Center, Marine Biological Laboratory, Woods Hole, MA 02543, USA

${ }^{4}$ Nicholas School of the Environment and Earth Sciences, and Department of Biology, Duke University, Durham, NC 27708, USA

${ }^{5}$ Ecology \& Evolutionary Biology, University of California, Irvine, CA 92697, USA

${ }^{6}$ Natural Resource Ecology Laboratory, Colorado State University, Fort Collins, CO 80523, USA

*Correspondence: E-mail: markb@uga.edu

Author e-mails: cdavies@uga.edu, serita.frey@unh.edu, trmaddox@uga.edu, jmelillo@mbl.edu, jmohan@uga.edu,james.f.reynolds@duke.edu, treseder@uci.edu,mawallen@nrel.colostate.edu Short running title: Thermal adaptation of soil respiration

Keywords: Acclimation, adaptation, soil respiration, thermal biology, temperature, carbon cycling, climate change, climate warming, microbial community, $\mathrm{CO}_{2}$

Type of article: Letter

Abstract 150 words; manuscript 4,961 words; 48 references; 4 figures and tables; mailing and email address of Mark A. Bradford is as above; tel. +1 706542 7829, fax. +1 7065423344 


\begin{abstract}
In the short-term heterotrophic soil respiration is strongly and positively related to temperature. In the long-term its response to temperature is uncertain. One reason for this is because in field experiments increases in respiration due to warming are relatively short-lived. The explanations proposed for this ephemeral response include depletion of fast-cycling, soil carbon pools and thermal adaptation of microbial respiration. Using a >15 year soil warming experiment in a midlatitude forest, we show that the apparent 'acclimation' of soil respiration at the ecosystem scale results from combined effects of reductions in soil carbon pools and microbial biomass, and thermal adaptation of microbial respiration. Mass specific respiration rates were lower when seasonal temperatures were higher, suggesting that rate reductions under experimental warming likely occurred through temperature-induced changes in the microbial community. Our results imply that stimulatory effects of global temperature rise on soil respiration rates may be lower than currently predicted.
\end{abstract}

\title{
Keywords
}

Acclimation, adaptation, soil respiration, thermal biology, temperature, carbon cycling, climate change, climate warming, microbial community, $\mathrm{CO}_{2}$ 


\section{INTRODUCTION}

The respiration of heterotrophic microorganisms decomposing soil organic carbon (SOC) releases carbon dioxide $\left(\mathrm{CO}_{2}\right)$ from soils to the atmosphere. In the short-term, rates of SOC decomposition and hence soil microbial respiration are strongly dependent on temperature (Kirschbaum 2006). If this short-term dependence of respiration on temperature can be extrapolated to the long-term, then heterotrophic soil respiration rates should increase as global temperature rises. However, in field experiments elevated respiration rates under soil warming return to pre-warming values within a few years (Jarvis \& Linder 2000; Oechel et al. 2000; Luo et al. 2001; Rustad et al. 2001; Melillo et al. 2002; Eliasson et al. 2005). Theoretical models (Kirschbaum 2004; Eliasson et al. 2005; Knorr et al. 2005) attribute the temporal pattern of soil respiration under experimental warming to depletion of labile pools of SOC and there is indirect empirical support for this mechanism (Hartley et al. 2007). An alternative mechanistic explanation for the ephemeral response is that soil microbial respiration thermally adapts to increased temperatures (Oechel et al. 2000; Luo et al. 2001; Reichstein et al. 2005; Davidson \& Janssens 2006), a phenomenon which may weaken the positive effect of warming on soil respiration rates. We refer to these two hypotheses as 'substrate-depletion' and 'thermal adaptation', respectively.

In the context of heterotrophic soil respiration responses to elevated temperature, the term ‘thermal acclimation’ has recently been applied (e.g. Oechel et al. 2000; Luo et al. 2001; Kirschbaum 2004; Knorr et al. 2005) in a general sense to define adjustments in respiration that result from temperature-induced changes in microbial individuals, populations and/or communities. Use of the term 'acclimation' in such a general sense has been criticised because of the potential for genetic changes to contribute to adjustments in respiration rates (e.g. Hartley et 
al. 2008). Indeed, acclimation usually refers to physiological adjustments of individuals (or organs) in response to a single environmental factor under laboratory conditions. The term 'acclimitization' is approximately equivalent but is used in field studies, where causation is often difficult to ascribe to a single variable (Hochachka \& Somero 2002; Körner 2003). Henceforth, we refer to the adjustments of respiration rates, of soil microbes decomposing SOC, to temperature as 'thermal adaptation'. Such a broad use of this term has been recommended in the physiological literature (Hochachka \& Somero 2002) to encompass the suite of responses organisms exhibit to altered thermal regimes, ranging from instantaneous temperature compensation (Hazel \& Prosser 1974) to selection of beneficial mutations. We suggest that the term can also encompass shifts from cold- to warm-adapted microbial populations, as observed in aquatic systems (Hall et al. 2008), because temperature was likely an important selective agent giving rise to genotypes and/or species differentially adapted to different thermal regimes.

Here, we specifically define thermal adaptation as a decrease in heterotrophic soil respiration rates per unit microbial biomass in response to a sustained increase in temperature (and vice-versa for a decrease in temperature). It is important to normalise for biomass because adaptive responses to altered temperature involve changes in mass specific respiration rates $\left(R_{\text {mass }}\right)$ (Clarke 1993; Hochachka \& Somero 2002; Atkin \& Tjoelker 2003; Körner 2003; Clarke 2004; Tjoelker et al. 2008). Note that mechanisms involved in instantaneous temperature compensation (see Hazel \& Prosser 1974) do not affect $R_{\text {mass }}$ rates and so when we refer to thermal adaptation we include phenomena that range from physiological adjustment of individuals to species shifts.

Physiological adjustment of $R_{\text {mass }}$ is a common property of many organisms (Hazel \& Prosser 1974; Hochachka \& Somero 2002; Körner 2003), including microbes (Leroi et al. 1994; 
Porankiewicz et al. 1998; Lange \& Green 2005; Heinemeyer et al. 2006; Malcolm et al. 2008). Indeed, while elements of the pathways of respiratory metabolism (e.g. glycolysis and Krebs cycle) are highly conserved across the three kingdoms of life, members of all kingdoms exhibit thermal niches which are associated with predictable changes in the mass specific activities, thermal ranges and optima of respiratory metabolism (Hochachka \& Somero 2002). The evolutionary trade-offs giving rise to these phenomena are well established (for review see Hochachka \& Somero 2002). For example, enzymes adapted to higher temperatures typically have reduced conformational flexibility as a result of the need to maintain their binding structure, which is temperature-sensitive. In cooler environments the selective force of temperature on enzyme structural stability is reduced, permitting increased conformational flexibility and hence more rapid catalytic rates. This means that if cold- and warm-adapted individuals are compared at a temperature intermediate to which they are adapted then $R_{\text {mass }}$ rates will be higher for the cold-adapted individuals (Fig. 1).

To test current hypotheses (substrate-depletion vs. thermal adaptation) relating microbial activities to soil $\mathrm{CO}_{2}$ efflux, we sampled soils throughout 2006 from a long-term soil warming study. We assayed the soils to estimate labile SOC pool sizes, microbial biomass, and $R_{\text {mass }}$. Following approaches in thermal biology (e.g. Fig. 1 and Hochachka \& Somero 2002) we assayed $R_{\text {mass }}$ under non-limiting substrate conditions and at temperatures experienced by control soils in the field. We show that the apparent 'acclimation' of soil $\mathrm{CO}_{2}$ efflux at the ecosystem scale occurs concomitantly with substrate depletion and thermal adaptation of $R_{\text {mass }}$ at the microbial scale. We also show that seasonal variation in temperature explains a significant proportion of the variance in $R_{\text {mass }}$ across 2006. 


\section{METHODS}

\section{Study site}

The soil warming experiment was established in 1991 on the Prospect Hill tract of the Harvard Forest, Massachusetts, USA. The experiment is located in an even aged, mixed deciduous forest $\left(42.5^{\circ} \mathrm{N}, 72.18^{\circ} \mathrm{W}\right)$ dominated by black oak (Quercus veluntina), red maple (Acer rubrum), paper birch (Betula papyrifera) and striped maple (Acer pensylvanicum). Mean weekly air temperature at the site varies from $20^{\circ} \mathrm{C}$ in July to $-6^{\circ} \mathrm{C}$ in January. Precipitation is distributed evenly throughout the year and averages $108 \mathrm{~cm}_{\text {annum }}{ }^{-1}$. Soils are of the Gloucester series (fine loamy, mixed, mesic Typic Dystrochrept). We utilised twelve of the $6 \times 6 \mathrm{~m}$ experimental plots. These were grouped into six blocks, with plots in each block assigned to one of two treatments: (i) heated - soil temperatures elevated $5^{\circ} \mathrm{C}$ above ambient using heating cables; (ii) control identical except cables received no power. Further details can be found in Peterjohn et al. (1994). As in other long-term warming studies (Oechel et al. 2000; Luo et al. 2001), previous work at this experimental site (Melillo et al. 2002) showed that the initially elevated rates of soil respiration in the heated soils returned to those of the control soils after the first few years of continuous warming.

\section{Soil sampling}

Soils were sampled $25^{\text {th }}$ April, $19^{\text {th }}$ July, $17^{\text {th }}$ October and $20^{\text {th }}$ November 2006 . At each sampling date, four soil cores (2.5 cm dia.) were collected from each field plot. Cores were separated into two depth increments: organic horizon and the first $10 \mathrm{~cm}$ of the mineral horizon. We used surface soils because they tend to be where microbial activity, and hence contributions to heterotrophic soil respiration, are highest. Soils were sieved to $2 \mathrm{~mm}$, screened to remove 
remaining root and litter fragments, and then bulked and homogenised within each horizon and plot to provide 24 samples ( 12 plots $\times 2$ horizons). These were sent overnight, on ice, to the University of Georgia for analysis.

\section{Soil and microbial biomass analyses}

The 24 soils per sampling date were assayed for labile SOC pools and microbial biomass, extractable inorganic and organic nitrogen pools, and soil moisture. Soils were assayed in duplicate for all variables. Microbial biomass was estimated using a modified (Fierer et al. 2003) substrate-induced respiration (SIR) technique and modified chloroform-fumigation extraction (CFE, Fierer \& Schimel 2003). Given there is no one ideal method for measuring microbial biomass, we used two methods to establish whether similar treatment responses were observed (Coleman et al. 2004). We report SIR biomass as the maximum $\mathrm{CO}_{2}$ production rates (soil + substrate-derived) and CFE biomass as the flush of extractable dissolved organic carbon (DOC) released following chloroform-fumigation (e.g. Fierer \& Schimel 2003). The modified SIR method we employed involves short $\left(4 \mathrm{~h}\right.$ ) incubations of soil slurries at $20^{\circ} \mathrm{C}$ after a $1 \mathrm{~h}$ preincubation with excess substrate; this may overcome some of the limitations associated with the method if microbes are actively growing (see Blagodatsky et al. 2000).

There is also no one ideal method for resolving meaningful SOC pools (Olk \& Gregorich 2006; von Lützow et al. 2007) and so again we used two methods. For the first method, soils were maintained at $20^{\circ} \mathrm{C}$ and $65 \%$ water-holding capacity (WHC) for $60 \mathrm{~d}$ with periodic determinations of respiration rates using a static incubation technique (Fierer et al. 2005) and infra-red gas analysis (IRGA) of headspace $\mathrm{CO}_{2}$ concentrations. Mineralizable carbon was estimated as the area under the curve derived by plotting $\mathrm{CO}_{2}$ production against time. This 
method provides a coarse estimate of microbially available carbon (e.g. Bradford et al. 2008). For the second method, we shook soils with $0.5 \mathrm{M} \mathrm{K}_{2} \mathrm{SO}_{4}$ for $4 \mathrm{~h}$, filtered the extracts and determined DOC concentrations using a Total Organic Carbon Analyzer (Shimadzu, Columbia, USA). DOC is a complex soup of multiple SOC compounds, including both low and high molecular weight compounds (van Hees et al. 2005). Extractable DOC is, however, used to estimate labile carbon availability (e.g. Cleveland \& Townsend 2006).

From the DOC extract solutions we also quantified total inorganic and dissolved organic nitrogen using standard colorimetric techniques and persulfate digests. Soil moisture contents and water-holding capacities were determined by drying 'fresh' soil subsamples at $105^{\circ} \mathrm{C}$ until constant mass, or after they'd been wetted beyond field-capacity and permitted to drip drain for 2 h, respectively. These data were used in the seasonal regression analyses of $R_{\text {mass }}$ (see below).

\section{Thermal adaptation assays}

We tested for thermal adaptation by conducting short-term assays, following similar approaches as in plant and animal thermal adaptation studies (e.g. Hochachka \& Somero 2002; Atkin \& Tjoelker 2003; Malcolm et al. 2008; Tjoelker et al. 2008). These short-term assays permit measurement of $R_{\text {mass }}$ before the individuals (or in our case communities) can thermally adapt to the assay incubation temperatures. That is, measured $R_{\text {mass }}$ values should be representative of those in situ. The assays involved incubating soils with water or ${ }^{13} \mathrm{C}$-labelled sucrose, at $65 \%$ WHC, for $24 \mathrm{~h}$ simultaneously at 10,15 and $20^{\circ} \mathrm{C}$ prior to determination of headspace $\mathrm{CO}_{2}$ concentrations and ${ }^{13} \mathrm{C}$ contents. Use of ${ }^{13} \mathrm{C}$-labelled sucrose minimized variation in measured respiration rates that might be caused by differential utilization for respiration of compounds in the SOC as temperature increases (e.g. Fierer et al. 2005; Knorr et al. 2005; Davidson \& 
Janssens 2006). The incubation temperatures spanned the range experienced by the control soils across our study period (see Fig. S1 in Supplementary Material). We used $50 \mathrm{~mL}$ centrifuge tubes, with caps modified for gas analysis. Each tube contained 2 g dry weight equivalent soil and, after sucrose or water addition, was capped and then flushed with $\mathrm{CO}_{2}$-free air to remove $\mathrm{CO}_{2}$ from the headspace prior to incubation. Sucrose solution was added to organic and mineral soils at doses of 42.5 and $21 \mathrm{mg} \mathrm{C} \mathrm{g} \mathrm{dry} \mathrm{soil}{ }^{-1}$, respectively. Dose-response experiments confirmed these amounts were in excess of demand, which avoided the confounding effect of substrate-limitation when assessing the response of enzyme-catalysed reactions to temperature (Davidson et al. 2006). The necessity of removing substrate-limitation means that our assays reflect the $R_{\text {mass }}$ rates of the proportion of the soil microbial biomass which can utilise sucrose. This proportion is probably large: indeed, sucrose was used as a representative disaccharide, which are dominant constituents of rhizodeposited carbon (van Hees et al. 2005), which itself supports much of heterotrophic soil respiration. ${ }^{13} \mathrm{C}$ concentrations in sucrose were $\sim 1000 \%$.

The isotopic difference between sucrose- and soil-derived $\mathrm{CO}_{2}$ was used to quantify mineralization of the sucrose using isotope mixing models. Following Ineson et al. (1996), respiration of sucrose was calculated as: $C_{\text {mineralized }}=C_{\text {pool }} *\left(\delta^{13} C_{\text {final }}-\delta^{13} C_{\text {soil }}\right) /\left(\delta^{13} C_{\text {sucrose }}-\delta^{13} C_{\text {soil }}\right)$, where $\mathrm{C}_{\text {pool }}$ is the mass of $\mathrm{CO}_{2}$ produced during the assay, $\delta^{13} \mathrm{C}_{\text {final }}$ the delta value of the headspace $\mathrm{CO}_{2}$ at the end of the incubation with sucrose, $\delta^{13} \mathrm{C}_{\text {soil }}$ is the value of $\mathrm{CO}_{2}$ respired from soil with only water added, and $\delta^{13} \mathrm{C}_{\text {sucrose }}$ is the value of the added substrate. This approach permitted us to estimate potential soil respiration rates, substrate respiration rates and also mass specific, substrate respiration rates (hereafter $R_{\text {mass }}$ ). Sucrose respiration rates were expressed per unit SIR microbial biomass to calculate $R_{\text {mass }}$. We used this adjustment because of the potential for SIR, with our incubation approach (see above), to most accurately estimate biomass. Results 
were approximately the same if adjusted by CFE biomass. This suggested that despite the fact we used a single temperature to estimate SIR, measurement at other temperatures would not have changed relative treatment effects on $R_{\text {mass }}$. Headspace $\mathrm{CO}_{2}$ concentrations were determined using IGRA and their stable isotope ratios using continuous flow, isotope ratio mass spectrometry (Thermo Scientific, San Jose, USA). Analytical precision was $\pm 0.1 \delta^{13} \mathrm{C} \%$. Working standards were calibrated to PDB using NIST-SRM 1577b Bovine Liver as a reference.

\section{Statistics}

To test for treatment, sampling date and soil horizon effects on microbial biomass, labile SOC pools, soil respiration rates, sucrose respiration rates and $R_{\text {mass }}$ we used linear mixed-effects modelling. Fixed effects were Date (April, July, October, November), Horizon (organic, mineral), Warming treatment (control, heated) and (for respiration data) Incubation assay temperature $\left(10,15,20^{\circ} \mathrm{C}\right)$. Given that $R_{\text {mass }}$ is essentially a ratio, we used the above model structure and a covariate approach to evaluate treatment effects (Jasienski \& Bazzaz 1999). The latter approach used microbial biomass as the covariate and sucrose respiration rates (not $R_{\text {mass }}$ ) as the dependent variable. Given that the simplest covariate model (single slope, multiple intercepts) was not significantly improved by more complex model structures, both approaches returned equivalent $P$ values for the model terms.

To identify the unit of repeated measurement across time and space, the random effects were defined as Sample (coded 1 to 24 across the 12 experimental plots and 2 soil horizons) nested within Field plot, nested within Block. Both Block and Field plot were dropped from the error structures of all models because the AIC values of the models with only Sample were consistently lower for all variables. Where there were significant interactions between Treatment 
and other fixed effects (i.e. the thermal adaptation data), sub-models were used to first analyse by horizon and then by date. All factors were treated as categorical variables (there is no reason to assume a linear response of respiration across measurement temperatures).

For linear regression analyses of seasonal variation in $R_{\text {mass }}$ against mean daily temperature, we calculated the mean daily temperature for the 3-days preceding sampling, then 7-days preceding sampling, then 14, 21, 28 and so on to 91-days preceding sampling. We performed regressions with each time step and continued until the variance explained no longer increased (which it did steadily until the point it then declined when longer time steps were used). We reported the time step where most variance was explained. Using linear regression, we evaluated whether other soil variables (e.g. mineralizable carbon) explained significant variation in seasonal values of $R_{\text {mass. }}$. Those that did were included in multiple regressions. We first fitted the simplest model (i.e. no interactions). Next, curvature was tested by fitting the quadratic terms for the variables. We then tested interactions and models were simplified using the 'step' function in S-Plus 8.0 (Insightful Corporation, Seattle, USA). We further tested whether models could be simplified by assessing whether models with a term removed differed significantly from more complex models. For statistical significance we assumed an $\alpha$-level of 0.05. All statistical analyses were performed in S-Plus 8.0. Data were tested for assumptions of normality and homogeneity of variance; in all linear-mixed effects models, respiration data were $\log _{\mathrm{e}}{ }^{-}$ transformed to meet these assumptions.

\section{RESULTS}

\section{Soil and microbial biomass analyses}


Mineralizable carbon and DOC pools were significantly lower in the heated compared to control soils (Treatment effect: $P<0.001$ and 0.01 , respectively). The relative magnitude of the treatment effect was consistent across sampling dates and soil horizons (i.e. $P>0.05$ for interactions between Treatment and Date and/or Horizon). SIR microbial biomass was significantly $(P<0.001)$ lower in the heated plots and, again, this effect was not influenced by Date nor Horizon (Table 1). In contrast, the treatment response of the CFE microbial biomass was horizon dependent (Treatment $\times$ Horizon interaction: $P<0.05$ ): it was lower in the heated plots for the organic soils (Treatment effect: $P<0.05$ ) but not the mineral soils (Treatment effect: $P=0.52$; Table 1).

\section{Thermal adaptation assays}

The design of our thermal adaptation assays permitted us to assess three different response variables. The 'water only' assays permitted estimation of potential soil respiration rates. For this variable treatment effects might be caused by substrate-depletion, thermal adaptation and/or differences in microbial biomass. The sucrose addition assays permitted estimation of a variable to test whether treatment effects on potential soil respiration rates resulted from substratedepletion (because it was removed), or whether thermal adaptation and/or differences in microbial biomass played a role. The sucrose mineralization rates, when divided by microbial biomass, permitted estimation of a third variable $\left(R_{\text {mass }}\right)$ to test whether thermal adaptation contributed to observed treatment effects on potential soil respiration rates. For clarity we show the log response ratios of the treatment effects for these three variables in Fig. 2 but our statistical analyses were performed on the flux rates (see Methods); these data are shown in Figs. S2-S4. 
Potential soil respiration rates were lower in heated than control soils at the same incubation assay temperature (Figs. 2 and S1). For the organic and mineral soils the treatment effect and/or treatment by incubation assay temperature interaction was, for each sampling occasion, significant (between $P<0.05$ and $P<0.001$, Fig. S2). The exception was the mineral soils sampled in October (Fig. S2). Sucrose respiration rates were significantly lower in heated than control soils across all sampling dates and both horizons (Treatment and/or Treatment $\times$ Incubation temperature effects of between $P<0.05$ and $P<0.001$; Figs. 2 and S3). Sucrose respiration rates were markedly higher than potential soil respiration rates (compare Figs. S2 and S3).

Sucrose respiration rates expressed per unit microbial biomass (i.e. as $R_{\text {mass }}$ ) were approximately equivalent for control and heated organic soils (Treatment and Treatment $\times$ Incubation temperature effects of $P>0.05$; Figs. 2 and S4). In contrast, rates of $R_{\text {mass }}$ were significantly lower in heated mineral soils (Treatment and/or Treatment $\times$ Incubation temperature effects of between $P<0.05$ and $P<0.001$; Figs. 2 and S4). This effect was consistent across sampling dates (Fig. S4). Ratios of control to heated $R_{\text {mass }}$ were lower (but still $>0$ ) than sucrose respiration rates per se (Fig. 2). Notably, for both soil horizons, in the cooler sampling months (April and November) $R_{\text {mass }}$ rates increased steeply between 10 to $15^{\circ} \mathrm{C}$ incubation assay temperatures, but differed slightly between 15 and $20^{\circ} \mathrm{C}$ (Fig. S4). In contrast, in the warmer sampling months (July and October) the change in $R_{\text {mass }}$ rates was slight across 10 to $15^{\circ} \mathrm{C}$ but large from 15 to $20^{\circ} \mathrm{C}$ (Fig. S4).

\section{Seasonal thermal adaptation}


Following the approach used in plant respiration studies (e.g. Tjoelker et al. 2008), we regressed $R_{\text {mass }}$ rates (measured at $15^{\circ} \mathrm{C}$, the 'intermediate' temperature) against the mean daily temperature in the days preceding soil sampling. Strong negative relationships between $R_{\text {mass }}$ rates and mean daily temperature (Fig. 3) were indicative of thermal adaptation in response to seasonal variation in temperature. Mean daily temperature across the preceding nine (for the organic horizon) and eleven (for the mineral horizon) weeks explained the greatest amount of variation (as much as $83 \%$ ) in $R_{\text {mass }}$ rates (Fig. 3).

To assess the potential for variables other than temperature to explain changes in $R_{\text {mass }}$ rates, we regressed $R_{\text {mass }}$ rates at $15^{\circ} \mathrm{C}$ against seasonal data for mineralizable carbon, DOC, microbial biomass, soil moisture and extractable dissolved organic and inorganic nitrogen. None of the variables explained $>14 \%$ of the seasonal variation in $R_{\text {mass }}$ rates of the mineral soils. In contrast, we observed significant negative relationships between $R_{\text {mass }}$ rates in organic soils and mineralizable carbon $\left(r^{2}=0.20, P<0.01, n=48\right)$ and SIR microbial biomass $\left(r^{2}=0.22, P<0.001\right.$, $n=48)$. The simplest multiple regression model of these variables and mean daily temperature (0.0492T-0.00002MinC-0.004Biomass+0.0002TBiomass +1.296 ) explained an additional 15\% of the seasonal variation in $R_{\text {mass }}$ rates of organic soils $\left(r^{2}=0.79, P<0.001, n=48\right)$.

\section{DISCUSSION}

The prediction that fast-cycling SOC pools become depleted in response to sustained warming (Kirschbaum 2004; Eliasson et al. 2005; Knorr et al. 2005) was supported by our data indicating that labile SOC pools were consistently lower in heated soils (Table 1). Concomitant with this reduction in labile SOC pools, and as also predicted by multi-pool SOC models (Kirschbaum 2004; Eliasson et al. 2005; Knorr et al. 2005), potential soil respiration rates were lower in 
heated soils at the same measurement temperature (Figs. 2 and S2). However, on alleviation of carbon substrate-limitation, respiration rates in heated soils remained below those of control soils (Figs. 2 and S3). This observation suggested that respiration differences between control and heated soils at the same measurement temperature were not solely explained by substratedepletion. Thus, reductions in microbial biomass and/or $R_{\text {mass }}$ rates may also be contributing to the apparent acclimation of soil respiration in this warming experiment.

SIR microbial biomass was lower in heated treatment soils (Table 1) and, in the organic horizon, the same effect was observed for CFE microbial biomass (Table 1). When substrate respiration rates were expressed per unit microbial biomass (i.e. as $R_{\text {mass }}$ ), rates in control and heated organic soils were approximately equivalent (Figs. 2 and S4), suggesting that lower biomass and not thermal adaptation explained lower respiration rates in heated organic soils when substrate-limitation was alleviated. In contrast, for the mineral soils, $R_{\text {mass }}$ rates were consistently lower in heated soils (Figs. 2 and S4). Ratios of control to heated $R_{\text {mass }}$ rates were lower (but still >0) than substrate respiration rates per se (Fig. 2), suggesting that reductions in microbial biomass and thermal adaptation likely both contribute to experimental warminginduced reductions in respiration rates in the mineral soils.

The lower microbial biomass in the heated soils is not trivial for the debate about longerterm responses of soil respiration to elevated temperature. Neither the substrate-depletion nor thermal adaptation hypotheses explicitly state that reductions in microbial biomass might partially explain the gradual return of soil respiration rates in heated field plots to those of controls (e.g. Oechel et al. 2000; Luo et al. 2001; Melillo et al. 2002). Indeed, multi-pool SOC models that have been used to examine the ephemeral response of soil respiration to experimental warming (Kirschbaum 2004; Eliasson et al. 2005; Knorr et al. 2005) do not take 
into account warming-related changes in the biomass of microbial communities (see Eliasson et al. 2005). The reductions in the size of fast-cycling SOC pools in these models, in response to warming, arise despite the fact that carbon inputs to the soil are assumed not to change (e.g. Kirschbaum 2004). This assumption of a constant carbon input rates implies that, once respiration rates in heated plots have returned to those of controls, microbial biomass in heated soils will be supplied with carbon at the same rate as microbial biomass in control soils. To ascertain whether smaller but more rapidly-cycling pools of labile SOC under warming will change microbial biomass requires multi-pool SOC models that explicitly model the microbial biomass as the agent through which SOC is mineralized. Such models could then investigate the relative contributions thermal adaptation of $R_{\text {mass }}$, substrate- depletion and decreases in microbial biomass make to the gradual decline in stimulation of soil respiration as the duration of warming is extended.

Our observation that $R_{\text {mass }}$ rates in mineral soils were reduced in response to experimental warming is consistent with the current understanding of biochemical adaptation to elevated temperature regimes (see Hochachka \& Somero 2002). Thermal adaptation in $R_{\text {mass }}$ of the mineral soils exhibited traits of Type I and II adaptation (Figs. 1 and S4) at different sampling occasions. That is, significant interactions between treatment and incubation assay temperature (Fig. S4) indicate different relative temperature sensitivities of $R_{\text {mass }}$ and hence Type I adaptation. Also, lower $R_{\text {mass }}$ rates for heated soils at the lowest incubation temperature (Figs. 2 and S4), and/or a non-significant treatment by incubation temperature interaction (Fig. S4h), are indicative of Type II adaptation. Type I adaptation is associated with a change in $\mathrm{Q}_{10}$ and Type II adaptation is not (Atkin \& Tjoelker 2003). Our observation that changes in $R_{\text {mass }}$ rates can occur without a necessary change in $\mathrm{Q}_{10}$ provides empirical data to support the suggestion that the 
body of work investigating soil respiration responses to elevated temperature needs to move beyond the restrictive focus on $\mathrm{Q}_{10}$ (Davidson et al. 2006). To emphasize this need, the seasonal shifts in the apparent temperature 'optimum' of $R_{\text {mass }}$ (peaking at $\sim 15^{\circ} \mathrm{C}$ in colder but not warmer sampling months; see Fig. S4) is indicative of Type III adaptation (Fig. 1). Notably, the temperature sensitivities of extracellular, soil microbial enzymes have also been shown to track seasonal changes in temperature (Fenner et al. 2005). Our work suggests $R_{\text {mass }}$ rates of the microbial biomass may also do so.

Given the reductions in labile SOC and microbial biomass in response to experimental warming we could not identify elevated temperature as the definitive cause of lower $R_{\text {mass }}$ in heated mineral soils (e.g., substrate-depletion could be argued to have been the causation of lower $\left.R_{\text {mass }}\right)$. For this reason, and in light of the uncertainty as to whether soil microbial respiration will thermally adapt to elevated temperatures (Davidson \& Janssens 2006; Davidson et al. 2006; Hartley et al. 2007), we evaluated $R_{\text {mass }}$ responses to temperature variation that were independent of the warming treatment. Strong negative relationships between $R_{\text {mass }}$ rates and mean daily temperature in both soil horizons (Fig. 3) were indicative of thermal adaptation in response to seasonal variation in temperature. Rates of $R_{\text {mass }}$ varied up to fourfold seasonally (Fig. 3) but at most twofold in response to the warming treatment (Fig. 2). This distinction probably occurred because temperature differences were about five times greater among seasons than between treatments (Fig. S1).

The observation that $R_{\text {mass }}$ in both the organic and mineral soils changed in response to seasonal variation in temperature (Figs. 3 and S4) demonstrates the potential for soil microbial respiration to thermally adapt to climate warming. However, it does not explain why we observed experimental warming-induced reductions in $R_{\text {mass }}$ in the mineral soils only. None of 
the soil variables we measured explained more than $14 \%$ of the seasonal variation in $R_{\text {mass }}$ rates of the mineral soils but, for the organic soils, both mineralizable carbon and SIR biomass correlated with rates of $R_{\text {mass }}$. We cannot definitively identify causation using regression approaches but our findings suggest that, in addition to temperature, decreased labile SOC and biomass may play a role in experimental warming-induced reductions in $R_{\text {mass. }}$ Future research priorities for understanding long-term effects of climate warming on soil respiration should include a more detailed understanding of the mechanisms underlying variation in $R_{\text {mass. }}$ Indeed, if carbon substrate-depletion does reduce $R_{\text {mass }}$ rates then increases in labile carbon supply to soils under elevated atmospheric $\mathrm{CO}_{2}$ may mitigate potential warming-induced reductions in $R_{\text {mass }}$. If so, realised $R_{\text {mass }}$ rates will be dependent on interactions between multiple global changes. Of these, changes in rainfall should certainly be considered given the pronounced effects of moisture on soil microbial respiration (Davidson et al. 2006).

The variance in seasonal $R_{\text {mass }}$ rates explained by mean daily temperature is comparable to that observed for thermal adaptation of plant respiration to seasonal temperature variation (Tjoelker et al. 2008). However, plant studies usually consider mean daily temperatures in the few days preceding measurements of $R_{\text {mass }}$ (Tjoelker et al. 2008), whereas mean daily temperatures in the 3-7 days preceding our soil sampling explained $<35 \%$ of the variation in $R_{\text {mass }}$ rates. Thermal adaptation of plant respiration is usually measured on genetically-similar individuals but the soil microbial biomass consists of multiple populations of many different species. The much longer time period ( 2.5 months) that best predicted $R_{\text {mass }}$ rates in our study suggests that heterotrophic microbes decomposing SOC either have slow physiological responses or, perhaps more probably, that the thermal adaptation we observed resulted from population or species shifts. Soil microbial communities are known to change in composition seasonally (e.g. 
Schadt et al. 2003; Waldrop \& Firestone 2006) and recent work (Hall et al. 2008) with freshwater bacterial communities suggests such shifts are associated with changes from cold- to warm-adapted populations as temperatures fluctuate across seasons. However, the precise mechanisms underlying the changes in $R_{\text {mass }}$ rates that we observed can only be speculative. Experimental warming effects on soil microbial community composition have only sometimes been observed (e.g. Zogg et al. 1997; Bardgett et al. 1999) and the effects of higher temperature regimes on the $R_{\text {mass }}$ rates of pure cultures of soil fungi have been shown to be species specific (Malcolm et al. 2008). Furthermore, direct linkages between microbial community composition and ecosystem processes are unresolved (Fierer et al. 2007; Allison \& Martiny 2008; Green et al. 2008). Fundamental research to investigate how microbial physiology and community composition is related to ecosystem processes is required to determine those mechanisms which explain why we observed thermal adaptation of the $R_{\text {mass }}$ rates of heterotrophic soil microbes.

\section{Conclusions}

Well-established evolutionary trade-offs in controls on metabolic rates suggest that mass specific respiration rates should be lower for organisms adapted to higher temperature regimes (Hochachka \& Somero 2002). Following the expectations generated by these trade-offs, our data demonstrate that soil microbial respiration thermally adapts to seasonal variation in temperature and that the ephemeral augmentation of soil $\mathrm{CO}_{2}$ efflux in response to experimental warming likely results, in part, from thermal adaptation of $R_{\text {mass }}$ rates of soil microbes. We also provide empirical support that substrate-depletion, as well as reductions in microbial biomass, likely contributes to the short-lived response of soil respiration to experimental warming. The changes 
in the biomass and physiology of soil microbial communities that we observed may decrease the expected strength of climate warming on soil respiration rates.

\section{ACKNOWLEDGEMENTS}

Isotope and element analyses were performed in the Analytical Chemistry Laboratory, Odum

School of Ecology, Univ. of Georgia. Michael S. Strickland, Agustina Hein and Jaya Srivistava provided technical support. We thank John Gittleman and Josh Schimel for comments on previous versions of this manuscript; Mark G. Tjoelker for advice on analysis, interpretation and presentation of thermal adaptation data; and Andrew Clarke for discussion about thermal adaptation of respiration. This research was supported by the Office of Science (BER), U.S. Department of Energy and the Andrew W. Mellon Foundation.

\section{REFERENCES}

Allison S.D. \& Martiny J.B.H. (2008). Resistance, resilience, and redundancy in microbial communities. P. Natl. Acad. Sci. U.S.A., 105, 115212-11519.

Atkin O.K. \& Tjoelker M.G. (2003). Thermal acclimation and the dynamic response of plant respiration to temperature. Trends Plant Sci., 8, 343-351.

Bardgett R.D., Kandeler E., Tscherko D., Hobbs P.J., Bezemer T.M., Jones T.H. \& Thompson

L.J. (1999). Below-ground microbial community development in a high temperature world. Oikos, 85, 193-203.

Blagodatsky S.A., Heinemeyer O. \& Richter J. (2000). Estimating the active and total soil microbial biomass by kinetic respiration analysis. Biol. Fert. Soils, 32, 73-81. 
Bradford M.A., Fierer N., Jackson R.B., Maddox T.R. \& Reynolds J.F. (2008). Nonlinear rootderived carbon sequestration across a gradient of nitrogen and phosphorous deposition in experimental mesocosms. Global Change Biol., 14, 1113-1124.

Clarke A. (1993). Seasonal acclimatization and latitudinal compensation in metabolism: do they exist? Funct. Ecol., 7, 139-149.

Clarke A. (2004). Is there a Universal Temperature Dependence of metabolism? Funct. Ecol., 18, 252-256.

Cleveland C.C. \& Townsend A.R. (2006). Nutrient additions to a tropical rain forest drive substantial soil carbon dioxide losses to the atmosphere. P. Natl. Acad. Sci. U.S.A., 103, 10316-10321.

Coleman D.C., Crossley D.A., Jr \& Hendrix P.F. (2004). Fundamentals of Soil Ecology. $2^{\text {nd }}$ edn. Elsevier Academic Press, Burlington.

Davidson E.A. \& Janssens I.A. (2006). Temperature sensitivity of soil carbon decomposition and feedbacks to climate change. Nature, 440, 165-173.

Davidson E.A., Janssens I.A. \& Luo Y.Q. (2006). On the variability of respiration in terrestrial ecosystems: moving beyond $\mathrm{Q}_{10}$. Global Change Biol., 12, 154-164.

Eliasson P.E., McMurtrie R.E., Pepper D.A., Strömgren M., Linder S. \& Ågren G.I. (2005). The response of heterotrophic $\mathrm{CO}_{2}$ flux to soil warming. Global Change Biol., 11, 167-181.

Fenner N., Freeman C. \& Reynolds B. (2005). Observations of a seasonally shifting thermal optimum in peatland carbon-cycling processes; implications for the global carbon cycle and soil enzyme methodologies. Soil Biol. Biochem., 37, 1814-1821.

Fierer N., Bradford M.A. \& Jackson R.B. (2007). Toward an ecological classification of soil bacteria. Ecology, 88, 1354-1364. 
Fierer N., Craine J.M., McLauchlan K. \& Schimel J.P. (2005). Litter quality and the temperature sensitivity of decomposition. Ecology, 86, 320-326.

Fierer N. \& Schimel J.P. (2003). A proposed mechanism for the pulse in carbon dioxide production commonly observed following the rapid rewetting of a dry soil. Soil Sci. Soc. Am. J., 67, 798-805.

Fierer N., Schimel J.P. \& Holden P.A. (2003). Variations in microbial community composition through two soil depth profiles. Soil Biol. Biochem., 35, 167-176.

Green J.L., Bohannan B.J.M. \& Whitaker R.J. (2008). Microbial biogeography: from taxonomy to traits. Science, 320, 1039.

Hall E.K., Nehauser C. \& Cotner J.B. (2008). Toward a mechanistic understanding of how natural bacterial communities respond to changes in temperature in aquatic ecosystems. ISME J., 1-11.

Hartley I.P., Heinemeyer A. \& Ineson P. (2007). Effects of three years of soil warming and shading on the rate of soil respiration: substrate availability and not thermal acclimation mediates observed response. Global Change Biol., 13, 1761-1770.

Hartley I.P., Hopkins D.W., Garnett M.H., Sommerkorn M. \& Wookey P.A. (2008). Soil microbial respiration in arctic soil does not acclimate to temperature. Ecol. Lett., DOI: 10.1111/j.1461-0248.2008.01223.x.

Hazel J.R. \& Prosser C.L. (1974). Molecular mechanisms of temperature compensation in poikilotherms. Physiol. Rev., 54, 620-677.

Heinemeyer A., Ineson P., Ostle N. \& Fitter A.H. (2006). Respiration of the external mycelium in the arbuscular mycorrhizal symbiosis shows strong dependence on recent photosynthates and acclimation to temperature. New Phytol., 171, 159-170. 
Hochachka P.W. \& Somero G.N. (2002). Biochemical Adaptation: Mechanism and Process in Physiological Evolution. Oxford Univ. Press, New York.

Ineson P., Cotrufo M.F., Bol R., Harkness D.D. \& Blum H. (1996). Quantification of soil carbon inputs under elevated $\mathrm{CO}_{2}$ : $\mathrm{C}_{3}$ plants in a $\mathrm{C}_{4}$ soil. Plant Soil, 187, 345-350.

Jarvis P. \& Linder S. (2000). Constraints to growth of boreal forests. Nature, 405, 904-905.

Jasienski M. \& Bazzaz F.A. (1999). The fallacy of ratios and the testability of models in biology. Oikos, 84, 321-326.

Kirschbaum M.U.F. (2004). Soil respiration under prolonged soil warming: are rate reductions caused by acclimation or substrate loss? Global Change Biol., 10, 1870-1877.

Kirschbaum M.U.F. (2006). The temperature dependence of organic-matter decomposition—still a topic of debate. Soil Biol. Biochem., 38, 2510-2518.

Knorr W., Prentice I.C., House J.I. \& Holland E.A. (2005). Long-term sensitivity of soil carbon turnover to warming. Nature, 433, 298-301.

Körner C. (2003). Alpine Plant Life. $2^{\text {nd }}$ edn. Springer, Berlin.

Lange O.L. \& Green T.G.A. (2005). Lichens show that fungi can acclimate their respiration to seasonal changes in temperature. Oecologia, 142, 11-19.

Leroi A.M., Bennett A.F. \& Lenski R.E. (1994). Temperature acclimation and competitive fitness: an experimental test of the beneficial acclimation assumption. P. Natl. Acad. Sci. USA, 91, 1917-1921.

Luo Y., Wan S., Hui D. \& Wallace L.L. (2001). Acclimatization of soil respiration to warming in a tall grass prairie. Nature, 413, 622-625. 
Malcolm G.M., López-Gutiérrez J.C., Koide R.T. \& Eissenstat D.M. (2008). Acclimation to temperature and temperature sensitivity of metabolism by ectomycorrhizal fungi. Global Change Biol., 14, 1169-1180.

Melillo J.M., Steudler P.A., Aber J.D., Newkirk K., Lux H., Bowles F.P., Catricala C., Magill A., Ahrens T. \& Morrisseau S. (2002). Soil warming and carbon-cycle feedbacks to the climate system. Science, 298, 2173-2176.

Oechel W.C., Vourlitis G.L., Hastings S.J., Zulueta R.C., Hinzman L. \& Kane D. (2000). Acclimation of ecosystem $\mathrm{CO}_{2}$ exchange in the Alaskan Arctic in response to decadal climate warming. Nature, 406, 978-981.

Olk D.C. \& Gregorich E.G. (2006). Overview of the symposium proceedings, "Meaningful pools in determining soil carbon and nitrogen dynamics". Soil Sci. Soc. Am. J., 70, 967-974.

Peterjohn W.T., Melillo J.M., Steudler P., Newkirk K.M., Bowles F. \& Aber J.D. (1994). Responses of trace gas fluxes and $\mathrm{N}$ availability to experimentally elevated soil temperatures. Ecol. Appl., 4, 617-625.

Porankiewicz J., Schelin J. \& Clarke A.K. (1998). The ATP-dependent Clp protease is essential for acclimation to UV-B and low temperature in the cyanobacterium Synechococcus. Mol. Microbiol., 29, 275-283.

Reichstein M., Kätterer T., Andrén O., Ciais P., Schulze E.-D., Cramer W., Papale D. \& Valentini R. (2005). Does the temperature sensitivity of decomposition vary with soil organic matter quality? Biogeosci. Discuss., 2, 737-747.

Rustad L., Campbell J.L., Marion G.M., Norby R.J., Mitchell M.J., Hartley A.E., Cornelissen J.H.C. \& Gurevitch J. (2001). A meta-analysis of the response of soil respiration, net 
nitrogen mineralization, and aboveground plant growth to experimental ecosystem warming. Oecologia, 126, 543-562.

Schadt C.W., Martin A.P., Lipson D.A. \& Schmidt S.K. (2003). Seasonal dynamics of previously unknown fungal lineages in tundra soils. Science, 301, 1359-1361.

Tjoelker M.G., Oleksyn J., Reich P.B. \& Zytkowiak R. (2008). Coupling of respiration, nitrogen, and sugars underlies convergent temperature acclimation in Pinus banksiana across wideranging sites and populations. Global Change Biol., 14, 782-797.

van Hees P.A.W., Jones D.L., Finlay R., Godbold D.L. \& Lundström U.S. (2005). The carbon we do not see-the impact of low molecular weight compounds on carbon dynamics and respiration in forest soils: a review. Soil Biol. Biochem., 37, 1-13.

von Lützow M., Kögel-Knabner I., Ekschmitt K., Flessa H., Guggenberger G., Matzner E. \& Marschner B. (2007). SOM fractionation methods: Relevance to functional pools and to stabilization mechanisms. Soil Biol. Biochem., 39, 2183-2207.

Waldrop M.P. \& Firestone M.K. (2006). Seasonal dynamics of microbial community composition and function in oak canopy and open grassland soils. Microbial Ecology, 52, 470-479.

Zogg G.P., Zak D.R., Ringelberg D.B., MacDonald N.W., Pregitzer K.S. \& White D.C. (1997). Compositional and functional shifts in microbial communities due to soil warming. Soil Science Society of America Journal, 61, 475-481.

\section{SUPPLEMENTARY MATERIAL}

The following supplementary material is available for this article:

Figure S1 Mean daily temperatures in control and heated soils at $10 \mathrm{~cm}$ depth across 2006. 
Figure S2 Rates of potential soil respiration in control and heated soils at three measurement temperatures.

Figure S3 Rates of soil microbial respiration of sucrose in control and heated soils at three measurement temperatures.

Figure S4 Rates of soil microbial respiration of sucrose, expressed per unit active microbial biomass (i.e. $R_{\text {mass }}$ ), in control and heated soils at three measurement temperatures.

This material is available as part of the online article from:

http://www.blackwell-synergy.com/doi/full/10.1111/j.1461-0248.XXXX.XXXXX.X

Please note: Blackwell Publishing is not responsible for the content or functionality of any supplementary materials supplied by the authors. Any queries (other than missing material) should be directed to the corresponding author for the article. 
Table 1 Reductions in pools of mineralizable carbon (MinC), dissolved organic carbon (DOC) and substrate-inducible (SIR) and extractable (CFE) microbial biomass carbon in response to 15 years of soil warming.

\begin{tabular}{|c|c|c|c|c|c|c|}
\hline Soil & Date & Treat & $\begin{array}{l}\text { MinC } \\
\left(\mu \mathrm{g} \mathrm{C} \mathrm{g} \mathrm{soil}{ }^{-1}\right)\end{array}$ & 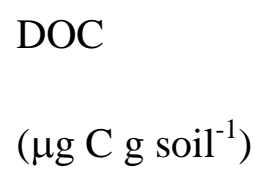 & $\begin{array}{l}\text { SIR } \\
\left(\mu \mathrm{g} \mathrm{C} \mathrm{g} \mathrm{soil}{ }^{-1} \mathrm{~d}^{-1}\right)\end{array}$ & $\begin{array}{l}\mathrm{CFE} \\
\left(\mu \mathrm{g} \mathrm{C} \mathrm{g} \mathrm{soil}{ }^{-1}\right)\end{array}$ \\
\hline \multirow[t]{8}{*}{ Org } & Apr & Control & $2839 \pm 256.4$ & $527 \pm 49.1$ & $132 \pm 6.8$ & $584 \pm 89.3$ \\
\hline & & Heated & $1880 \pm 109.5$ & $394 \pm 28.0$ & $97 \pm 5.9$ & $285 \pm 81.8$ \\
\hline & Jul & Control & $4349 \pm 176.1$ & $437 \pm 12.6$ & $231 \pm 8.7$ & $355 \pm 50.0$ \\
\hline & & Heated & $2564 \pm 327.0$ & $283 \pm 24.7$ & $152 \pm 16.5$ & $295 \pm 82.7$ \\
\hline & Oct & Control & $4247 \pm 209.5$ & $526 \pm 31.0$ & $147 \pm 9.9$ & $275 \pm 19.7$ \\
\hline & & Heated & $3626 \pm 387.1$ & $449 \pm 26.2$ & $113 \pm 11.5$ & $193 \pm 24.5$ \\
\hline & Nov & Control & $3401 \pm 248.9$ & $481 \pm 18.4$ & $53 \pm 3.8$ & $163 \pm 37.1$ \\
\hline & & Heated & $2633 \pm 249.0$ & $333 \pm 24.2$ & $48 \pm 4.0$ & $56 \pm 13.5$ \\
\hline \multirow[t]{5}{*}{ Min } & Apr & Control & $469 \pm 80.3$ & $542 \pm 53.9$ & $31 \pm 2.4$ & $184 \pm 19.6$ \\
\hline & & Heated & $316 \pm 27.4$ & $404 \pm 15.2$ & $20 \pm 1.4$ & $188 \pm 20.0$ \\
\hline & Jul & Control & $675 \pm 30.7$ & $317 \pm 39.8$ & $56 \pm 2.4$ & $112 \pm 22.6$ \\
\hline & & Heated & $476 \pm 60.4$ & $274 \pm 35.9$ & $33 \pm 2.6$ & $90 \pm 14.4$ \\
\hline & Oct & Control & $786 \pm 77.7$ & $410 \pm 48.9$ & $40 \pm 5.3$ & $114 \pm 15.8$ \\
\hline
\end{tabular}




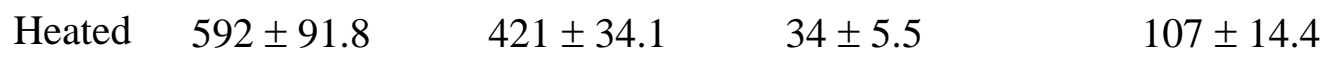

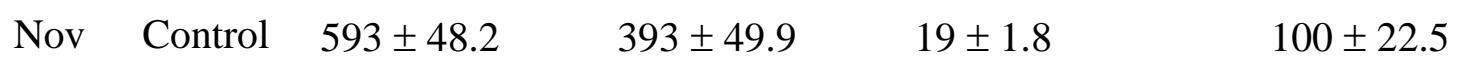

$$
\begin{array}{llll}
\text { Heated } & 366 \pm 36.2 & 352 \pm 54.3 & 12 \pm 1.3
\end{array}
$$

Soil horizon: organic (org) and mineral (min); Date: month in 2006 in which soils were

collected. Values are means \pm 1 s.e.m., $n=6$. 
Figure 1 Theoretical examples of three types of thermal adaptation of soil microbial respiration to warming. In each scenario (a-c) respiration rates are expressed per unit microbial biomass ( $\left.R_{\text {mass }}\right)$. Expression as $R_{\text {mass }}$ corrects for differences in measured respiration rates that arise through differences in microbial biomass. To account for differences in $R_{\text {mass }}$ that might arise because of substrate-limitation, these examples represent short-term (e.g. a few hours to a day) laboratory assays where substrate is added in excess of microbial demand. The 'control' and 'heated' treatments refer to the temperature regimes in situ; 'low', 'intermediate' and 'high' represent temperatures for the assays only. For the purposes of this example, the selected assay temperatures are considered to span the theoretical temperature range across which the respiratory enzymes in the experimental controls are active. In situ temperatures for the control soils will be near the 'low' value and for the heated soils near the 'high' value. As such, the 'intermediate’ assay temperature falls approximately between the control and heated in situ temperatures. The definitive test (e.g. Hochachka \& Somero 2002; Atkin \& Tjoelker 2003; Körner 2003) for thermal adaptation involves $R_{\text {mass }}$ at the intermediate temperature being lower for soils maintained in the heated than control treatment, as shown in each scenario a-c. Arrows denote the change in the temperature response function of $R_{\text {mass }}$ when thermally adapted to the higher temperature regime. Types I and II adaptation are based on those described by Atkin \& Tjoelker (2003). Type I adaptation (a) involves a decrease in the $\mathrm{Q}_{10}$ of $R_{\text {mass }}$ for soils adapted to higher temperatures and so results in no change in $R_{\text {mass }}$ at low temperatures but lower $R_{\text {mass }}$ (than the controls) at intermediate and higher measurement temperatures. Type II adaptation (b) takes the form of lower $R_{\text {mass }}$ values at all measurement temperatures and no decrease in $\mathrm{Q}_{10}$ is required to observe this effect (as in the scenario shown here). Type III adaptation (c) might involve a switch from cold- to warm-adapted populations, as described for freshwater bacterial 
communities (Hall et al. 2008), where the optimum temperature for $R_{\text {mass }}$ is shifted to a higher temperature (see Hochachka \& Somero 2002). All three types of adaptation may occur simultaneously in soil microbial communities. Based on the understanding of biochemical adaptation to temperature (see Hochachka \& Somero 2002) types I and II may result from the physiological adjustment of individuals, species turnover and/or adaptation, whereas type III adaptation likely only results from the latter two processes.

Figure 2 Log response ratios of soil microbial respiration in control and heated soils at three measurement temperatures. Field soils were sampled from control and heated plots $(n=6)$ and then assayed in the laboratory to assess potential respiration rates across a temperature range from 10 to $20^{\circ} \mathrm{C}$. These assays were performed for soils from the organic (a-d) and upper mineral (e-h) horizons across early spring (April) to late fall (November). Values are the natural log of ratios of the mean control and heated respiration rates presented in Figs. S2-S4. Ratios $>0$ indicate that respiration rates were greater in control than heated plots and vice-versa for ratios $<0$. Three measures of respiration are presented: 'Soil $R$ ' values (light grey bars) are respiration rates where substrate has not been added to alleviate carbon substrate-limitation and values are not corrected for differences in microbial biomass; 'Substrate $R$ ' values (white bars) are rates of sucrose mineralization where the substrate is in excess of microbial demand. 'Substrate $R_{\text {mass }}$ ' values (dark grey bars) are 'Substrate $R$ ' values corrected for differences in microbial biomass, and ratios $>0$ for $R_{\text {mass }}$ may arise through one or more of the thermal adaptation scenarios presented in Fig. 1. Note the different scales of the y-axes. In general, for both soil horizons, rates of Soil $R$ were significantly higher (Fig. S2) in control than heated soils (i.e. ratios $>0$ ) and these significantly greater control rates were maintained when substrate-limitation was alleviated (i.e. ratios of Substrate $R>0$; Fig. S3). In general, rates of Substrate $R_{\text {mass }}$ were not significantly 
different (Fig. S4) in the organic horizon (ratios close to or equal to 0) but were consistently, significantly greater (Fig. S4) in the mineral control than heated soils, indicative of thermal adaptation. Standard error bars are propagated from the errors in the control and heated treatments (Figs. S2-S4).

Figure 3 Seasonal changes in specific rates of microbial respiration $\left(R_{\text {mass }}\right)$ at a common temperature. Data are substrate respiration rates, at $15^{\circ} \mathrm{C}$, expressed per unit active microbial biomass (i.e. $R_{\text {mass }}$ ) for the organic (a,b) and mineral (c,d) horizon soils. Each circle represents an $R_{\text {mass }}$ value for either a control (open circle) or heated (closed circle) replicate plot ( $\left.n=6\right)$ for each sampling date $(\mathrm{a}, \mathrm{c})$ or regressed against the mean daily temperature (at $10 \mathrm{~cm}$ depth in the soil) in the 63 (b) or 77 (d) days preceding sampling for measurement of $R_{\text {mass }}$. The negative relationships between mean daily temperature and $R_{\text {mass }}$ are indicative of thermal adaptation of microbial respiration to changing temperatures across the growing season. $R_{\text {mass }}$ at $15^{\circ} \mathrm{C}$ for the organic and mineral soils $=-0.0227 T+0.748$ and $-0.0179 T+0.491$, respectively. The amount of variance explained and the significance of the regression relationships for each soil horizon are shown in b and d. Within a horizon, for each treatment, $r^{2}$ and $P$ values were: $r^{2}=0.63, P<0.001$, $n=24$ (organic control); $r^{2}=0.69, P<0.001, n=24$ (organic heated); $r^{2}=0.63, P<0.001, n=24$ (mineral control); $r^{2}=0.83, P<0.001, n=24$ (mineral heated). 
Fig. 1
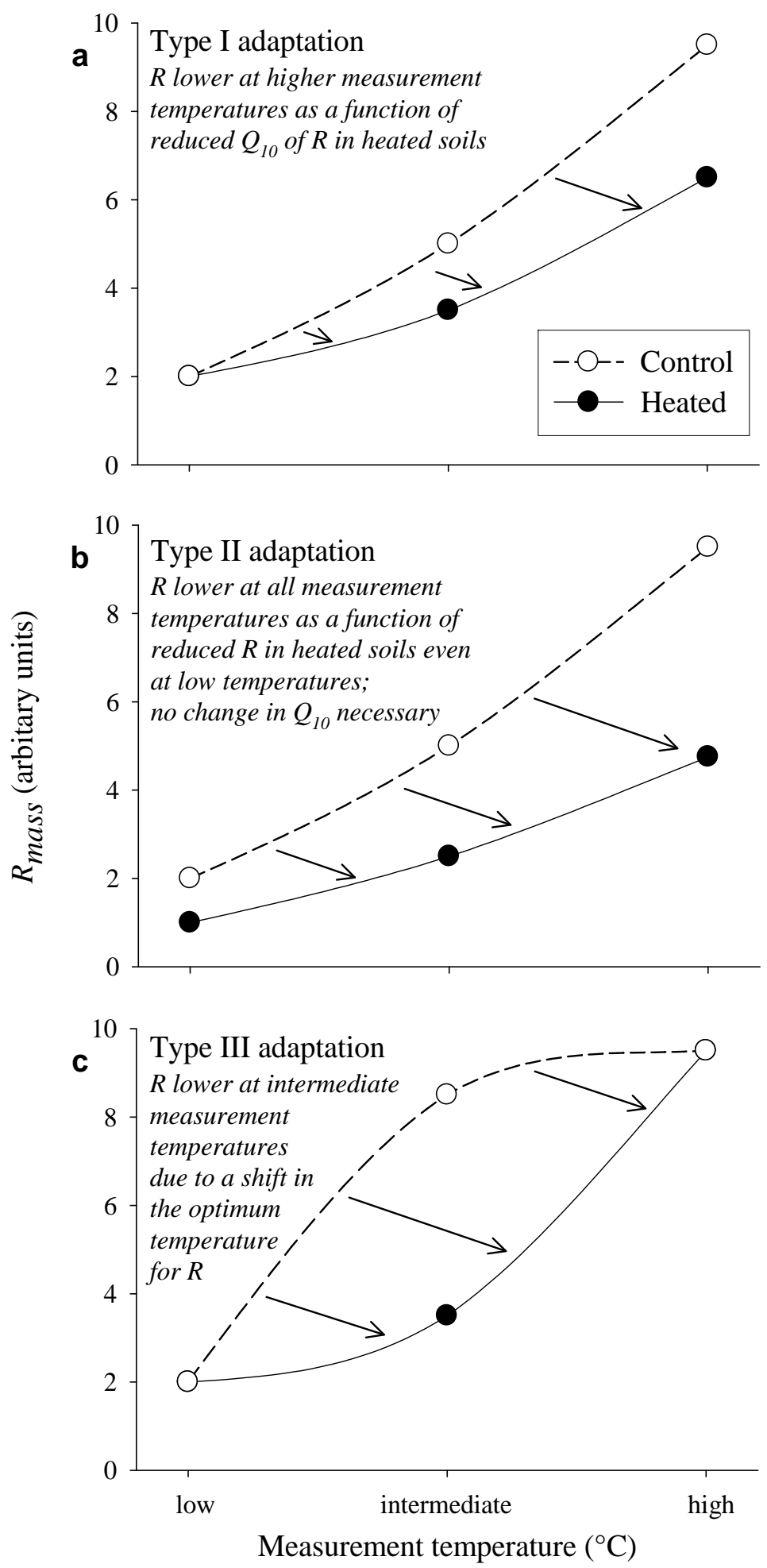
Fig. 2
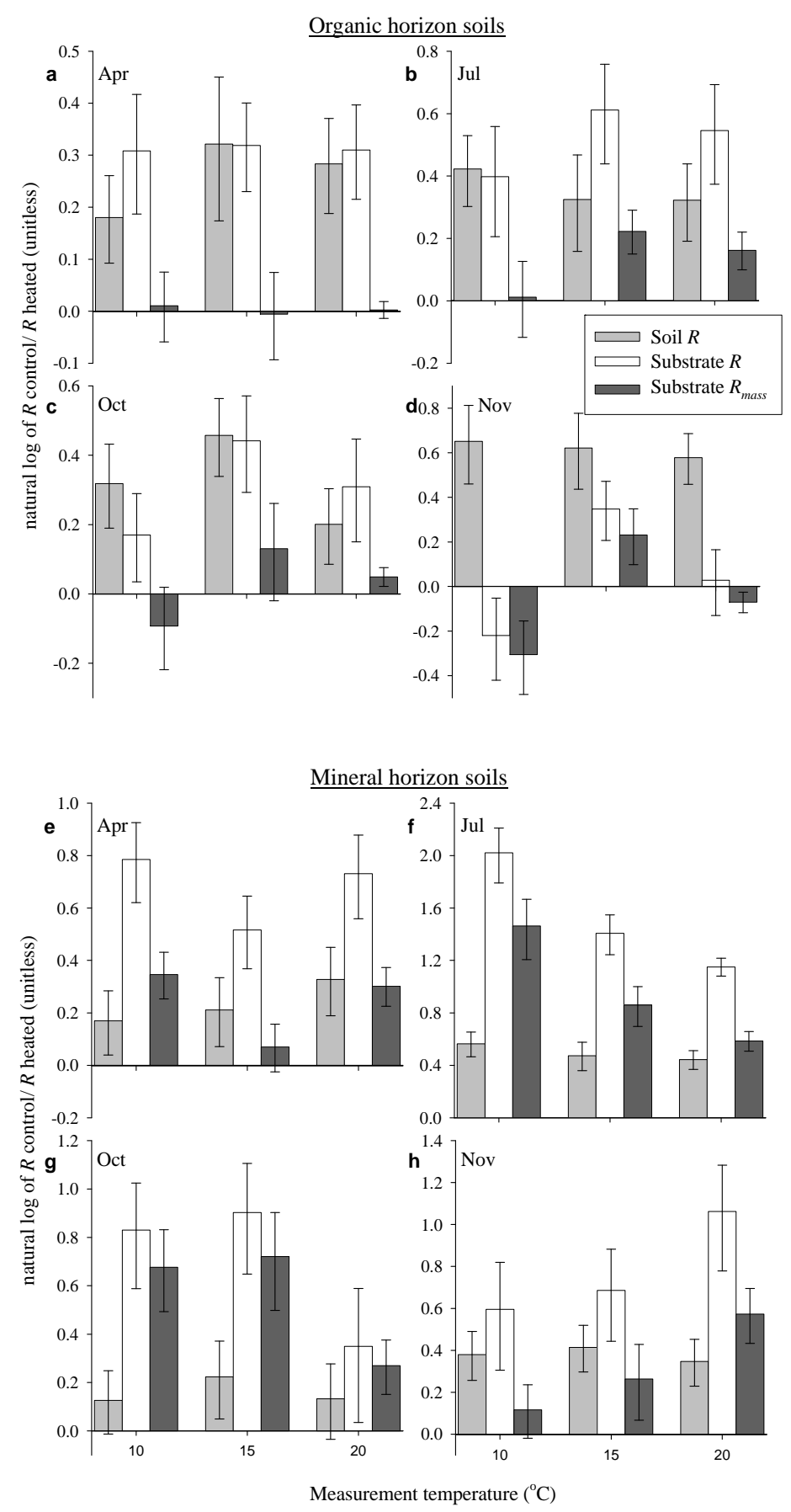
Fig. 3

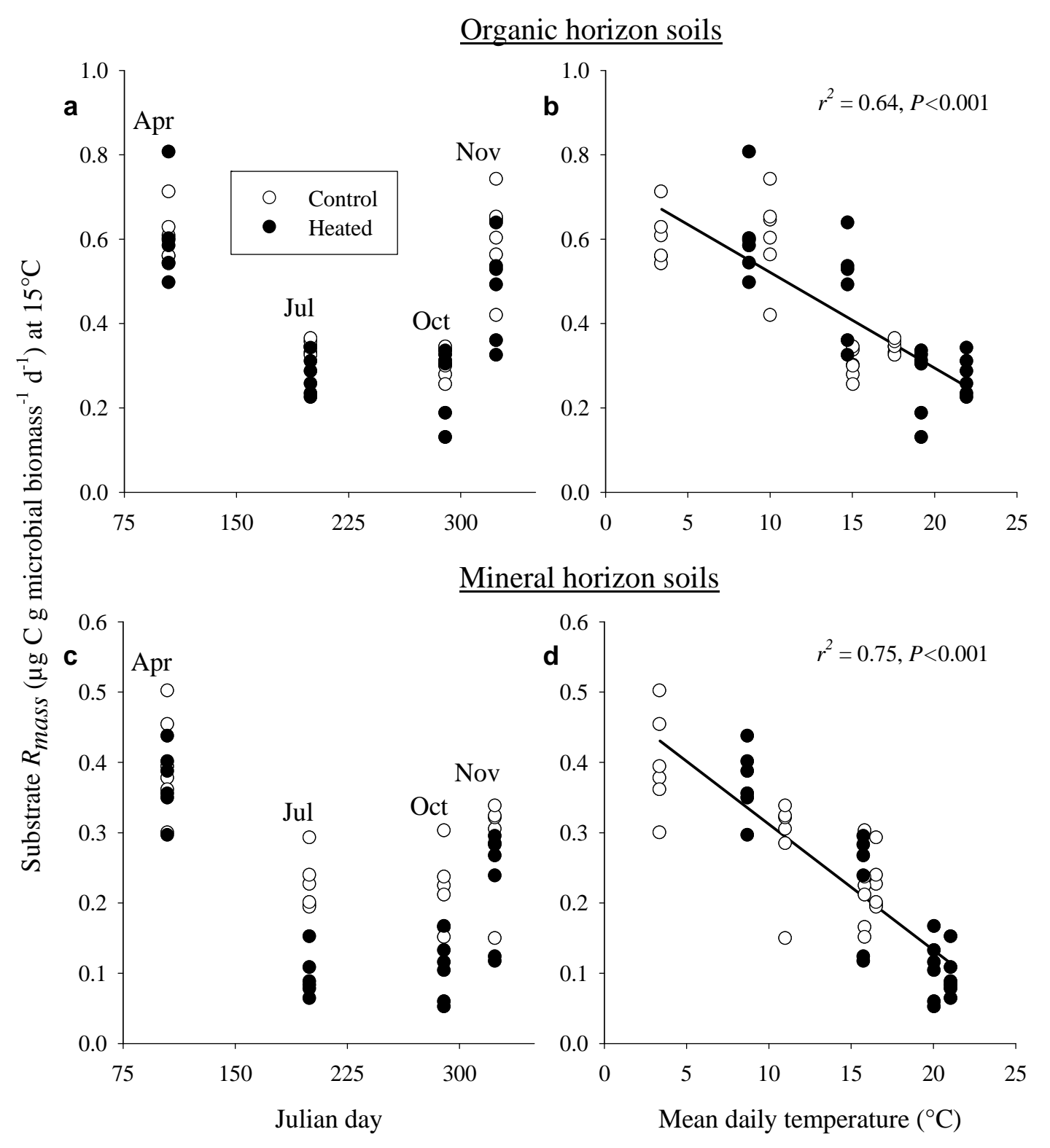

